\title{
Identification, Virulence, and Distribution of Two Biovars of Pseudomonas syringae pv. actinidiae in New Zealand
}

J. L. Vanneste, J. Yu, and D. A. Cornish, The New Zealand Institute for Plant \& Food Research Ltd., Hamilton 3240, New Zealand; D. J. Tanner, ZESPRI International Ltd., Mount Maunganui 3149, New Zealand; R. Windner, Kiwifruit Vine Health Inc., Mt Maunganui 3149, New Zealand; J. R. Chapman and R. K. Taylor, Plant Health and Environment Laboratory, Ministry for Primary Industries, Auckland 1140, New Zealand; J. F. Mackay, dnature diagnostics \& research Ltd., Gisborne 4010, New Zealand; and S. Dowlut, Verified Laboratory Services, Seeka Kiwifruit Industries, Te Puke, New Zealand

\begin{abstract}
Vanneste, J. L., Yu, J., Cornish, D. A., Tanner, D. J., Windner, R., Chapman, J. R., Taylor, R. K., Mackay, J. F., and Dowlut, S. 2013. Identification, virulence, and distribution of two biovars of Pseudomonas syringae pv. actinidiae in New Zealand. Plant Dis. 97:708-719.

Pseudomonas syringae pv. actinidiae, the causal agent of bacterial canker of kiwifruit, was detected for the first time in New Zealand in November 2010. Only in Bay of Plenty, one of the four regions where this pathogen had been detected, did symptoms evolve beyond leaf spots, resulting in cane die-back, wilting of canes, and canker, sometimes leading to death of the vine. Molecular analysis (cts haplotype and BOX-polymerase chain reaction [PCR] electrophoretic pattern) of strains isolated from different regions of New Zealand revealed that two biovars could be distinguished. They have been called biovar 3 and

Korea (biovar 2), which have a different cts haplotype or a different BOX-PCR pattern. Biovars 3 and 4 displayed different degrees of virulence, as measured by their ability to cause leaf spots on young, potted kiwifruit plants. Biovar 3, which has also been present in Italy since 2008 and in France, was found in the Bay of Plenty, where cane diebacks were observed. In contrast, no symptoms other than leaf spots have been observed in orchards where strains of biovar 4 have been isolated. We report the distribution and the disease progression of biovars 3 and 4 in New Zealand.
\end{abstract} biovar 4 to differentiate them from strains from Japan (biovar 1) or
Actinidia deliciosa and A. chinensis, the two most economically important species of kiwifruit in the world, are both susceptible to Pseudomonas syringae pv. actinidiae, the causal agent of bacterial canker of kiwifruit. This disease was first recorded in Japan in 1984 (35) and was subsequently found in Korea (20) and Italy (33). Affected vines exhibit leaf spots, cane wilting, cane die-back, and cankers, which are sometimes associated with copious production of a red or milky-white exudate. Although production of a red exudate is a common symptom of bacterial canker, the pathogen is not easily isolated from it (41). A similar red exudate can also be produced from apparently healthy tissues or vines nonaffected by $P$. syringae pv. actinidiae. It is produced, for example, in reaction to environmental stress such as frost damage. In contrast, $P$. syringae pv. actinidiae is readily isolated almost as a pure culture from the milky-white exudate that is sometimes produced by infected tissues, suggesting that this exudate consists of bacteria being extruded from the plant tissues (42). When conditions are favorable for development of the disease, $P$. syringae pv. actinidiae can kill a kiwifruit vine within a few months. $P$. syringae pv. actinidiae affects all commercial cultivars of kiwifruit, including the greenfleshed kiwifruit $A$. deliciosa 'Hayward' and 'Summer Kiwi', and the yellow-fleshed kiwifruit A. chinensis 'Jin Tao', 'Hort16A', and

Corresponding author: J. Vanneste,

E-mail: Joel.Vanneste@plantandfood.co.nz

* The $\boldsymbol{e}$-Xtra $\log$ stands for "electronic extra" and indicates that two supplementary figures appear in the online edition.

Accepted for publication 3 November 2012.

http://dx.doi.org/10.1094/PDIS-07-12-0700-RE

(c) 2013 The American Phytopathological Society
'Soreli'. In Europe, orchards of A. chinensis are, in general, more affected than the orchards of A. deliciosa (2). Bacterial canker is currently the most destructive disease of kiwifruit worldwide.

In Asia, P. syringae pv. actinidiae has had a serious economic impact on kiwifruit production, in some cases limiting the cultivation of kiwifruit $(21,34)$. Nevertheless, the effect of this disease in Asia has not been as destructive as its latest outbreak in Europe. Bacterial canker caused by $P$. syringae pv. actinidiae has been recently reported in several European countries: Italy $(2,11)$, Portugal (3), France (40), Spain (1), Switzerland (8), and Turkey (4). This epidemic, which was first reported in Latina (Italy) in 2008, has been devastating for the local kiwifruit industry. In several cases, orchards were totally destroyed and plants had to be pulled out because of bacterial canker; this outbreak jeopardized the cultivation of kiwifruit and, in particular, of $A$. chinensis, in the most important growing regions of Italy. This is in contrast to the first outbreak of the disease in Italy (1992), which had a very limited economic impact.

Although the difference in economic impact between the Asian and recent Italian outbreaks could be the result of different climatic conditions, the differences between the Italian outbreaks of 1992 and 2008 are more difficult to explain, given that the environmental conditions were similar. Furthermore, the differences between those two Italian outbreaks could not be attributed to differences in host susceptibility, because the two major commercial species of kiwifruit present in Italy in 2008 (A. deliciosa Hayward and A. chinensis Hort16A) had been present in that country for several years. Because neither the host nor the environment can explain the difference in economic impact of the two Italian outbreaks, our attention has turned to the pathogen. Recent molecular analyses have shown that the populations of $P$. syringae pv. actinidiae detected during the 2008 outbreak in Italy were different from those in Japan, Korea, or Italy during the 1992 outbreak $(12,28,41)$. Based on differences in the DNA sequence of the housekeeping 
gene coding for citrate synthase (cts) and BOX-polymerase chain reaction (PCR) electrophoretic patterns, the strains of $P$. syringae pv. actinidiae analyzed could be placed in two distinct groups (41). Strains isolated from Asia and those isolated in Italy before 2008 belong to one group, while all the strains isolated from Italy since 2008 belong to a second group. Because a major characteristic differentiating those two groups was differences in the DNA sequence of the $c t s$ gene, these groups were referred to as $c t s$ haplotype A and cts haplotype I (41).

In November 2010, P. syringae pv. actinidiae was isolated in New Zealand for the first time $(10,42)$. It was isolated from leaves, canes, and flowers of kiwifruit showing typical signs of infection $(10,42)$. Symptoms that led to the detection of $P$. syringae pv. actinidiae included angular leaf spots with or without a yellow halo and wilting of young shoots. In some cases, a white, milky exudate, from which the pathogen could be isolated, was also detected (42).

To establish the potential economic impact of this discovery, this project aimed to determine whether the strains of $P$. syringae pv. actinidiae isolated from New Zealand were similar to strains isolated overseas. Molecular analysis of strains isolated from different regions of New Zealand indicated that two groups of strains could be distinguished. These groups have been called biovar 3 and biovar 4 to separate them from strains with different molecular characteristics that were isolated from Japan (biovar 1) or Korea (biovar 2). Molecular characteristics (cts and ompPl sequences, BOX-PCR electrophoretic profiles, and presence of some effector genes such as $h o p A 1$ and $a v r D$ ), virulence (differences in virulence observed in the field could be replicated under laboratory conditions), and geographic distribution of the two biovars of $P$. syringae pv. actinidiae found in New Zealand have been determined and are presented.

\section{Materials and Methods}

Strains and media. The strains of $P$. syringae pv. actinidiae, including the 44 strains isolated from New Zealand and characterized during the course of the study, are presented in Table 1. The pathotype strain ICMP 9617 and strain ICMP 9855 were obtained from the International Collection of Microorganisms from Plants (ICMP) held by Landcare Research New Zealand. All the strains were maintained on King's B (KB) medium (19) at $28^{\circ} \mathrm{C}$.

Collection of plant samples. Kiwifruit leaves analyzed for the presence of $P$. syringae pv. actinidiae usually showed symptoms of bacterial canker (i.e., small angular necrotic spots). However, leaves with other types of necrotic spots and symptomless leaves were also collected from orchards where the presence of $P$. syringae pv. actinidiae was either suspected or unknown (e.g., orchards located in proximity to orchards where $P$. syringae pv. actinidiae had been isolated). Leaves were sampled from every region of New Zealand where commercial kiwifruit orchards are located (Fig. 1). However, the majority of the samples came from the Bay of Plenty region of the North Island of New Zealand, which is the major growing area for kiwifruit and the area where the first outbreak of bacterial canker was reported. Because of the biosecurity status of $P$. syringae pv. actinidiae as an "unwanted organism" in New Zealand, the samples were collected, transported, and analyzed following protocols established by the Ministry for Primary Industries (MPI; formerly Ministry of Agriculture and Forestry [MAF]). The samples were double bagged immediately after collection and transported in a chilled polystyrene-insulated container to one of the following three Physical Containment Level 2 (PC2) laboratories: the Plant and Food Research Laboratory located in Hamilton (PFR), the Verified Laboratory Services laboratory (VLS) in Te Puke, or the MPI Plant Health and Environment Laboratory (PHEL) in Tamaki, Auckland. Between November 2010 and May 2011, samples from over 300 orchards nationwide were analyzed by PFR and over 900 were analyzed by PHEL; between 15 April 2011 and January 2012, more than 2,200 samples had been analyzed by VLS.

Bacterial isolation and biochemical characterization. Bacteria were isolated from leaves or canes using one of two methods.
Samples sent to PFR were isolated using the methods described by Vanneste et al. (42). Briefly, $100 \mu$ l of a washing solution obtained by vigorously rubbing each leaf for $2 \mathrm{~min}$ in $10 \mathrm{ml}$ of sterile distilled water was plated on $\mathrm{KB}$ medium containing a $1 \%$ solution of cycloheximide at $5 \mathrm{ml} /$ liter. When isolating from cane tissue, small sections were teased out in sterile water and the suspension was spread on plates of KB medium supplemented with cycloheximide. In both cases, after $28 \mathrm{~h}$ of incubation at $28^{\circ} \mathrm{C}, P$. syringae pv. actinidiae-like colonies were purified and characterized as described below. Samples sent to PHEL were isolated using the methods described by Chapman et al. (5). Briefly, leaves were surface sterilized with $70 \%$ ethanol; then, small pieces of tissue from the margins of lesions were ground in bacteriological saline $(0.85 \%$ $[\mathrm{wt} / \mathrm{vol}] \mathrm{NaCl})$, then left at room temperature for $10 \mathrm{~min}$. Aliquots of the macerated leaf tissue were streaked onto $\mathrm{KB}$ medium, incubated at $25^{\circ} \mathrm{C}$ overnight, and then subcultured onto $\mathrm{KB}$ medium to obtain single colonies.

Strains of $P$. syringae pv. actinidiae share some biochemical and molecular characteristics that set them apart from strains of other Pseudomonas spp. and strains of most other P. syringae pathovars. In particular, they are only slightly or nonfluorescent on KB medium, induce a hypersensitive reaction (HR) when infiltrated in tobacco plants, do not produce a cytochrome c oxidase or an arginine dihydrolase, produce levan, do not hydrolyze esculin, do not rot potato, do not produce syringomycin, and do not induce ice nucleation. The ability of a bacterial strain to induce an HR when injected into tobacco plants was tested as described previously (39). Absence of cytochrome c oxidase, a characteristic that differentiates $P$. syringae from other species of plant-pathogenic fluorescent Pseudomonas, was determined using Test Oxidase (Pro-Lab Diagnostic). For this assay, P. fluorescens (strain A506) (44) was used as a positive control and $P$. syringae pv. syringae (strain ICMP3523) was used as a negative control. Production of levan and of an arginine dihydrolase under anaerobic conditions and the ability to hydrolyze esculin were determined as described by Lelliot et al. (23). P. syringae pv. syringae (ICMP 3523) was used as a positive control for production of levan and hydrolysis of esculin. For production of an arginine dihydrolase, P. fluorescens (A506) was used as a positive control. The ability to rot potato was determined as described previously (36). Water was used as a negative control and a strain of Pectobacterium sp. isolated from kiwifruit was used as a positive control. Ice nucleation activity was determined as described by Lindow et al. (25). P. syringae pv. syringae (ICMP 3523) was used as a positive control and $P$. syringae pv. actinidiae (ICMP 9855 and ICMP 9617) was used as a negative control. Production of syringomycin was determined according to Gross and DeVay (15), with the following modifications: bacterial strains were grown at $28^{\circ} \mathrm{C}$ for $48 \mathrm{~h}$ in the center of a plate of potato dextrose agar (PDA) (Difco; Becton, Dickinson and Company) before a plug of Geotrichum candidum (ICMP 5442) was placed $50 \mathrm{~mm}$ away from the edge of the bacterial growth. After $48 \mathrm{~h}$ of incubation at room temperature, inhibition of $1 \mathrm{~mm}$ or more around the bacterial colonies indicated syringomycin production. $P$. syringae pv. atrofaciens (ICMP 4394) was used as a positive control and $P$. syringae pv. actinidiae (ICMP 9855 and ICMP 9617) was used as a negative control. To assess resistance to streptomycin, KB medium was supplemented with streptomycin (100 ppm). To assess resistance or tolerance to copper, bacteria were resuspended in $1 \mathrm{mM}$ solution of copper sulfate $\left(\mathrm{CuSO}_{4} \cdot 5 \mathrm{H}_{2} \mathrm{O}\right.$ at 250 $\mathrm{mg} / \mathrm{liter}$; BDH Laboratory Supplies) and incubated for $4 \mathrm{~h}$ at $28^{\circ} \mathrm{C}$, before being spread on KB medium without copper.

Identification and characterization of $P$. syringae pv. actinidiae by PCR. Total DNA from isolated colonies was isolated at PFR with a cell disruptor FastPrep-24 MP using the ZR fungal/bacterial DNA kit (Zymo Research), and at PHEL using the DNeasy Blood and Tissue Kit (Qiagen). PCRs were performed at PFR on an Eppendorf Mastercycler Gradient, in a total volume of $20 \mu \mathrm{l}$, using Intron Maxime PCR premix (INtRON Biotechnology Inc.), to which $10 \mathrm{pmol}$ of each primer and $1 \mu \mathrm{l}$ containing 50-100 ng of genomic DNA were added. At PHEL, PCRs were performed 
Table 1. Strains of Pseudomonas syringae pv. actinidiae used in this study

\begin{tabular}{|c|c|c|c|c|c|}
\hline Strain number & Host plant & Geographic origin & Year of isolation & Biovar & Source \\
\hline ISPAVE-B-019a & Actinidia deliciosa & Italy & 1994 & 1 & M. Scortichini \\
\hline ISPAVE-B-020 $0^{\mathrm{b}}$ & A. deliciosa & Italy & 1994 & 1 & M. Scortichini \\
\hline ICMP $9617^{c}$ & A. deliciosa & Japan & 1989 & 1 & ICMP $^{d}$ \\
\hline ICMP 9855 & A. deliciosa & Japan & 1989 & 1 & ICMP \\
\hline NIAS 302143 & A. deliciosa & Japan & 1987 & 1 & G. M. Balestra \\
\hline K-Psa 2 & Actinidia sp. & Korea & $\ldots$ & 2 & G. M. Balestra \\
\hline CRA-FRU 10.22 & A. chinensis & Italy & 2008 & 3 & M. Scortichini \\
\hline CRA-FRU 2.2 & A. chinensis & Italy & 2009 & 3 & M. Scortichini \\
\hline CRA-FRU 5.1 & A. deliciosa & Italy & 2009 & 3 & M. Scortichini \\
\hline CRA-FRU 8.76 & A. deliciosa & Italy & 2009 & 3 & M. Scortichini \\
\hline I-Psa H1 & A. deliciosa & Italy & 2008 & 3 & G. M. Balestra \\
\hline CFBP 7287 & A. deliciosa & Italy & 2008 & 3 & G. M. Balestra \\
\hline I-Psa H3 & A. deliciosa & Italy & 2008 & 3 & G. M. Balestra \\
\hline CFBP 7286 & A. chinensis & Italy & 2008 & 3 & G. M. Balestra \\
\hline I-Psa Z & A. chinensis & Italy & 2008 & 3 & G. M. Balestra \\
\hline I-Psa 8 & A. chinensis & Italy & 2008 & 3 & G. M. Balestra \\
\hline I-Psa G & A. chinensis & Italy & 2008 & 3 & G. M. Balestra \\
\hline CFBP 7285 & A. chinensis & Italy & 2008 & 3 & G. M. Balestra \\
\hline $219-8$ & Actinidia sp. & France & 2011 & 3 & 41 \\
\hline I-9.4.10-D1 & A. chinensis & Italy & 2010 & 3 & 41 \\
\hline I-9.4.10-D4 & A. chinensis & Italy & 2010 & 3 & 41 \\
\hline I-9.4.10-D3b & A. chinensis & Italy & 2010 & 3 & 41 \\
\hline I-9.4.10-E4 & A. chinensis & Italy & 2010 & 3 & 41 \\
\hline I-9.4.10-E7 & A. chinensis & Italy & 2010 & 3 & 41 \\
\hline I-9.4.10-E-Ab & A. chinensis & Italy & 2010 & 3 & 41 \\
\hline I-6.5.10-4.4 & A. chinensis & Italy & 2010 & 3 & 41 \\
\hline I-25.10.6.6 & A. chinensis & Italy & 2010 & 3 & 41 \\
\hline I-6.5.10 & A. chinensis & Italy & 2010 & 3 & 41 \\
\hline I.23.6.10 & A. chinensis & Italy & 2010 & 3 & 41 \\
\hline 10627 & A. chinensis & Te Puke, NZ & 2010 & 3 & This study \\
\hline 10635 & A.chinensis & Te Puke & 2010 & 3 & This study \\
\hline 10636 & A. deliciosa & Te Puke & 2010 & 3 & This study \\
\hline 10638 & A. chinensis & Te Puke & 2010 & 3 & This study \\
\hline 10639 & A. chinensis & Te Puke & 2010 & 3 & This study \\
\hline 10641 & A. chinensis & Te Puke & 2010 & 3 & This study \\
\hline 10642 & A. deliciosa & Te Puke & 2010 & 3 & This study \\
\hline 10787 & A. deliciosa & Te Puke & 2010 & 3 & This study \\
\hline 11264 & A. deliciosa & Te Puke & 2010 & 3 & This study \\
\hline 11265 & A. deliciosa & Te Puke & 2010 & 3 & This study \\
\hline 11266 & A. deliciosa & Te Puke & 2010 & 3 & This study \\
\hline 11268 & A. deliciosa & Te Puke & 2010 & 3 & This study \\
\hline 11269 & A. deliciosa & Te Puke & 2010 & 3 & This study \\
\hline 11271 & A. deliciosa & Te Puke & 2010 & 3 & This study \\
\hline 11282 & A. deliciosa & Te Puke & 2010 & 3 & This study \\
\hline 11283 & A. deliciosa & Te Puke & 2010 & 3 & This study \\
\hline 11284 & A. deliciosa & Te Puke & 2010 & 3 & This study \\
\hline 11285 & A. deliciosa & Te Puke & 2010 & 3 & This study \\
\hline 11287 & A. deliciosa & Te Puke & 2010 & 3 & This study \\
\hline 11290 & A. deliciosa & Te Puke & 2010 & 3 & This study \\
\hline 11291 & A. deliciosa & Te Puke & 2010 & 3 & This study \\
\hline 11293 & A. deliciosa & Te Puke & 2010 & 3 & This study \\
\hline 11297 & A. deliciosa & Te Puke & 2011 & 3 & This study \\
\hline 11298 & A. deliciosa & Te Puke & 2011 & 3 & This study \\
\hline 11301 & A. deliciosa & Te Puke & 2011 & 3 & This study \\
\hline 11302 & A. deliciosa & Te Puke & 2011 & 3 & This study \\
\hline 11303 & A. deliciosa & Te Puke & 2011 & 3 & This study \\
\hline 11305 & A. deliciosa & Te Puke & 2011 & 3 & This study \\
\hline 11311 & A. deliciosa & Te Puke & 2011 & 3 & This study \\
\hline 11318 & A. chinensis & Te Puke & 2011 & 3 & This study \\
\hline 11955 & A. deliciosa & Pukehina, NZ & 2011 & 3 & This study \\
\hline 12030 & A. deliciosa & Te Puke & 2011 & 3 & This study \\
\hline 12339 & A. deliciosa & Te Puke & 2011 & 3 & This study \\
\hline 10850 & A. chinensis & Motueka, NZ & 2010 & 4 & This study \\
\hline 10874 & A. chinensis & Motueka & 2010 & 4 & This study \\
\hline 10880 & A. chinensis & Motueka & 2010 & 4 & This study \\
\hline 10885 & A. chinensis & Motueka & 2010 & 4 & This study \\
\hline 10984 & A. chinensis & Hawke's Bay, NZ & 2010 & 4 & This study \\
\hline 10986 & A. chinensis & Hawke’s Bay & 2010 & 4 & This study \\
\hline 10988 & A. chinensis & Hawke's Bay & 2010 & 4 & This study \\
\hline 11248 & A. chinensis & Te Puke & 2010 & 4 & This study \\
\hline 11249 & A. chinensis & Te Puke & 2010 & 4 & This study \\
\hline 11251 & A. chinensis & Te Puke & 2010 & 4 & This study \\
\hline 11616 & A. deliciosa & Te Puke & 2011 & 4 & This study \\
\hline
\end{tabular}

a Also known as NCPPB 3871.

b Also known as NCPPB 3873.

c This is the pathotype of $P$. syringae pv. actinidiae.

d ICMP is the International Collection of Microorganisms from Plants held by Landcare Research New Zealand. 
on GeneAmp 9700 thermal cyclers (Applied Biosystems) using GoTaq Green mastermix (Promega Corp.) and concentrations of primers and DNA comparable with those used at PFR. For identification of $P$. syringae pv. actinidiae, four sets of primers were used. The primers Psa F1 (5'-TTTTGCTTTGCACACCCGATTTT-3') and Psa R2 (5'-TTTTGCTTTGCACACCCGATTTT-3'), which yield a 280-bp amplicon with DNA from strains of $P$. syringae pv. actinidiae, were used following the protocol described by Rees George et al. (31) and modified by Vanneste et al. (41). This assay was further modified for high-throughput testing by adapting it to real-time PCR, utilizing SYBR Green technology and melting curve analysis. This is the assay VLS used. DNA extracted from leaf material was directly analyzed, bypassing the need to isolate and purify bacterial colonies before characterization. Leaf punches were taken from suspect leaf spots and homogenized in buffer (VLS: Mini Beadbeater, BioSpec Products; PHEL: cetyltrimethylammonium bromide buffer followed by grinding on a Homex homogenizer). DNA was extracted from the resulting supernatant using manual (Plant Genomic DNA Mini Kit; Geneaid or Plant MiniKit; Qiagen) or automated (LabTurbo 48 or Kingfisher mL; Thermo Scientific) extraction platforms (VLS and PHEL, respectively, in both cases). The real-time PCR assay used $0.3 \mu \mathrm{M}$ Psa F1 and Psa R2 primers, $5 \mu$ of either PerfeCTa SYBR Green FastMix (Quanta BioSciences) (PFR) or SSO Fast EvaGreen supermix (Bio-Rad) (PHEL), and $2 \mu \mathrm{l}$ of extracted DNA in a 10- $\mu \mathrm{l}$ final volume reaction. Real-time PCR was performed on either the Eco real-time PCR System (Illumina) (VLS) or the CFX96 realtime PCR system (Bio-Rad) (PHEL) using a thermal cycling pro-

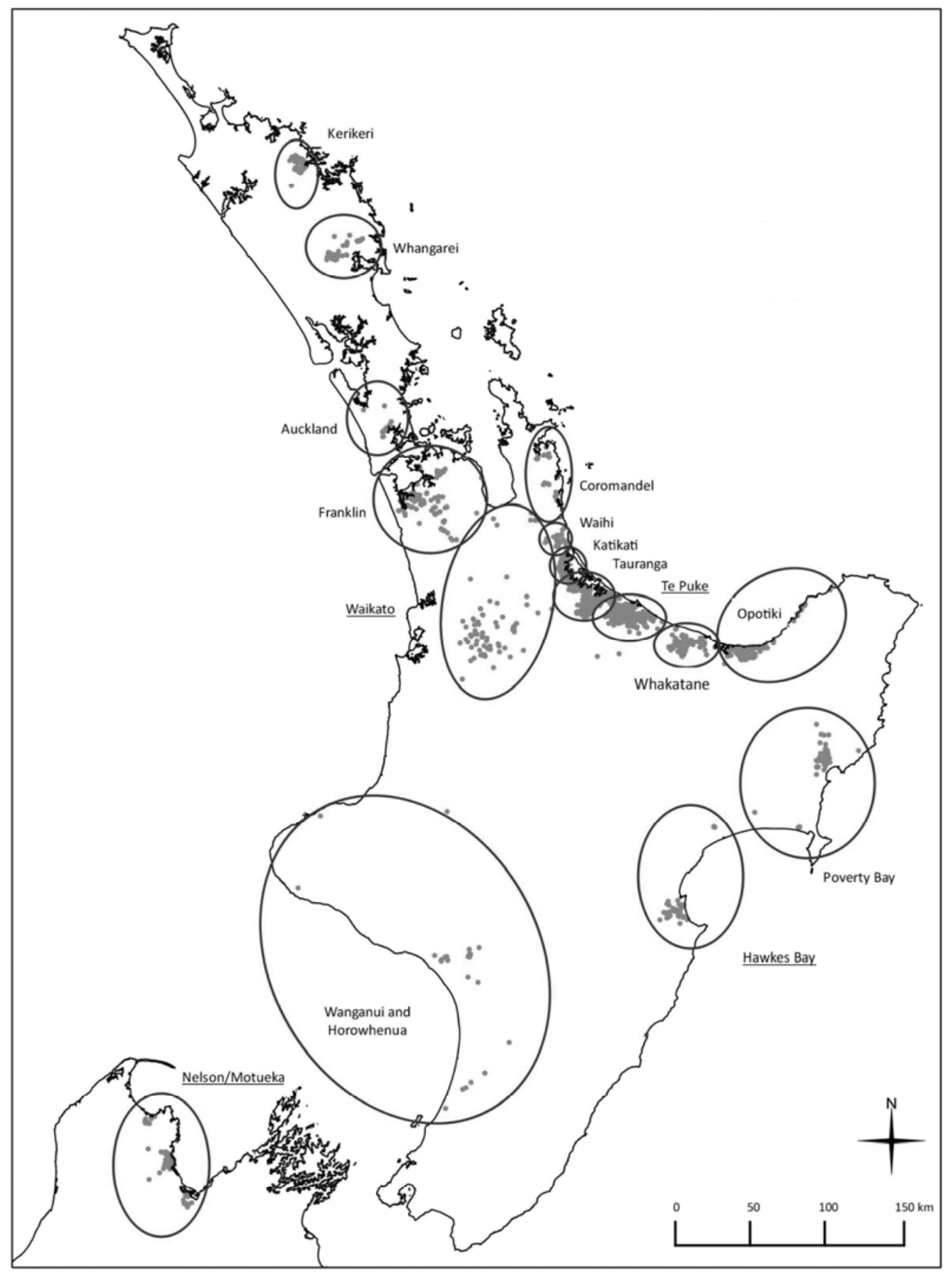

Fig. 1. Location of commercial kiwifruit-growing regions in New Zealand. The areas labeled Katikati, Tauranga, Te Puke, Whakatane/Edgecumbe, Opotiki, and Waihi constitute the Bay of Plenty. In November 2010, Pseudomonas syringae pv. actinidiae was isolated from the areas which are underlined (Te Puke, Hawke's Bay, Waikato, and Nelson/Motueka). 
gram of $95^{\circ} \mathrm{C}$ for 3 min followed by 43 cycles of $95^{\circ} \mathrm{C}$ for $5 \mathrm{~s}$ and $60^{\circ} \mathrm{C}$ for $20 \mathrm{~s}$. Default melting curve analysis $\left(80\right.$ to $95^{\circ} \mathrm{C}$ melt curve in $0.5^{\circ} \mathrm{C}$ increments, $2 \mathrm{~s}$ per increment) was then performed to verify the amplified product, because the 280-bp amplicon produced by $P$. syringae pv. actinidiae isolates generated a highly characteristic two-domain melting curve.

The Koh and Nou primers (forward: 5'-CACGATACATGG GCTTATGC-3' and reverse: 5'-CTTTTCATCCACACACTCCG- $3^{\prime}$ ), which yield a 492-bp amplicon, were used following the protocol published by Koh and Nou (22). The duplex protocol of Gallelli et al. (13) which, in addition to the Koh and Nou primers, uses the primers AvrDdpx-F (5'-TTTCGGTGGTAACGTTGGCA$\left.3^{\prime}\right)$ and AvrDdpx-R (5'-TTCCGCTAGGTGAAAAATGGG-3') to amplify a 226-bp portion of the $a v r D 1$ gene, was carried out as described by the authors (13). In addition, amplification of a 896bp fragment of the $16 \mathrm{~S}$ rDNA was carried out using the PCR pri-

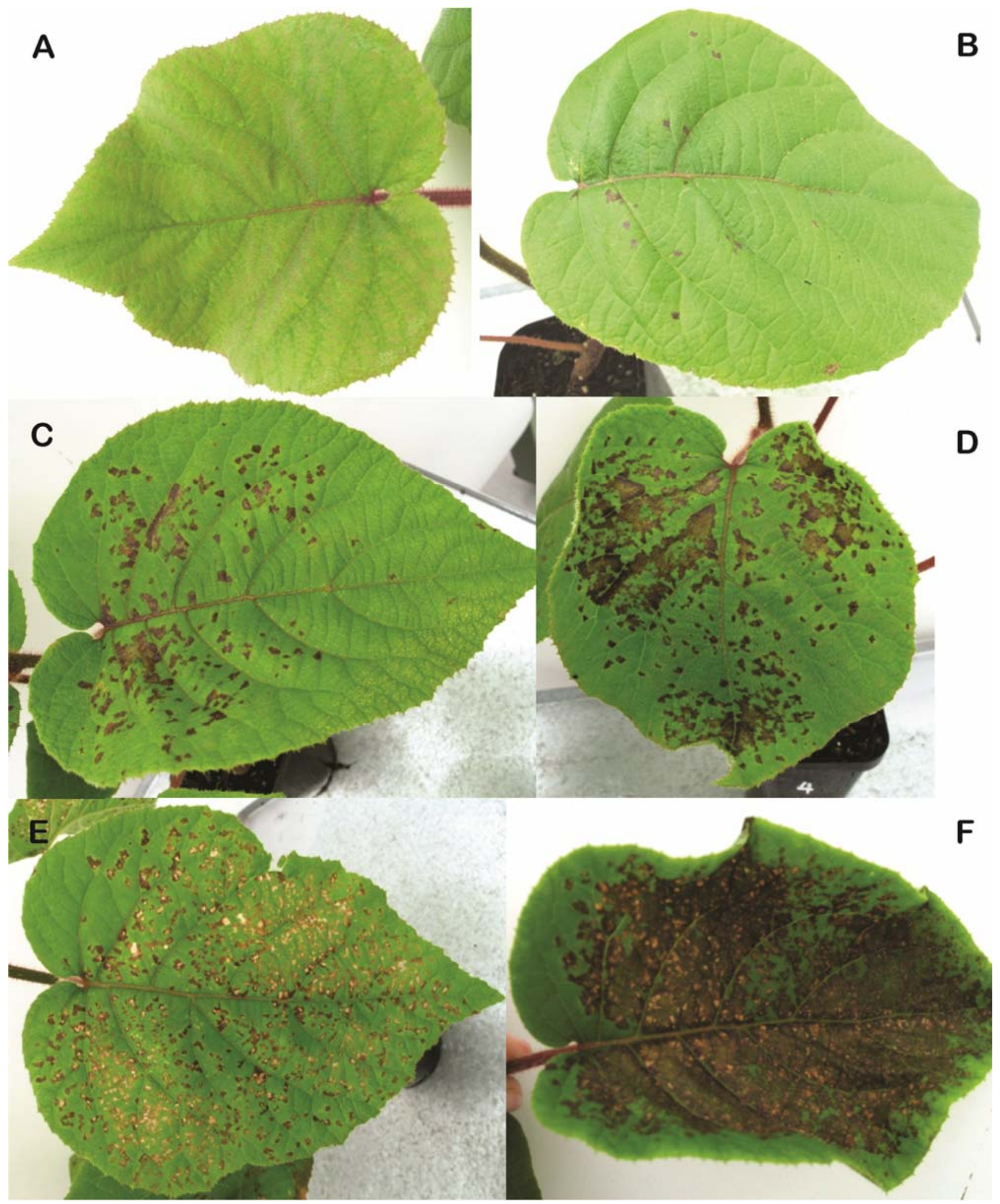

Fig. 2. Scoring system used for assessment of the virulence of Pseudomonas syringae pv. actinidiae, shown on leaves of Actinidia deliciosa 'Bruno'. Leaves were scored from 0 to 5 according to the percentage of leaf surface showing necrosis: (A) $0 \%$ necrosis was scored 0 , (B) 1-10\% of the leaf area necrosed was scored 1, (C) 11-25\% necrosis was scored 2, (D) 26-50\% necrosis was scored 3, (E) $51-75 \%$ necrosis was scored 4, and (F) $76-100 \%$ necrosis was scored 5. 
mers 11F (5'-GTTTGATCMTGGCTCAG-3') (14) and 907R (5'CCGTCAATTCMTTTGAGTTT-3') (30) as described earlier (14).

The $c t s$ gene, also known as gltA, was amplified using the primers cts-Fp ( $5^{\prime}$-AGTTGATCATCGAGGGCGCWGCC-3') and ctsRp (5'-TGATCGGTTTGATCTCGCACGG-3') and amplicons were then sequenced using the primers cts-Fs $\left(5^{\prime}\right.$-CCCGTCGAG CTGCCAATWCTGA- $\left.3^{\prime}\right)$ and cts-Rs (5'-ATCTCGCACGGS GTRTTGAACATC-3'), as described earlier (32). BOX-PCR was carried out using the primer BOXA1R (5'-CTACGGCAAGGC GACCTGACG-3'), as described by Louws et al. (26). The presence of the hopAl effector gene was detected by PCR using primers hopA1-F (5'CGGCAAGAGGTACGAGATTC-3') and hopA1-R (5'-TTCAATGCCTTTAGCGTGTG-3') (12).

When needed, PCR products were separated by horizontal gel electrophoresis on 1 or $2 \%$ agarose containing ethidium bromide or SYBR Safe DNA gel stain (Molecular Probes) at $10 \mathrm{ng} / \mathrm{ml}$. Between 5 and $20 \mu \mathrm{l}$ of each PCR reaction was loaded, along with

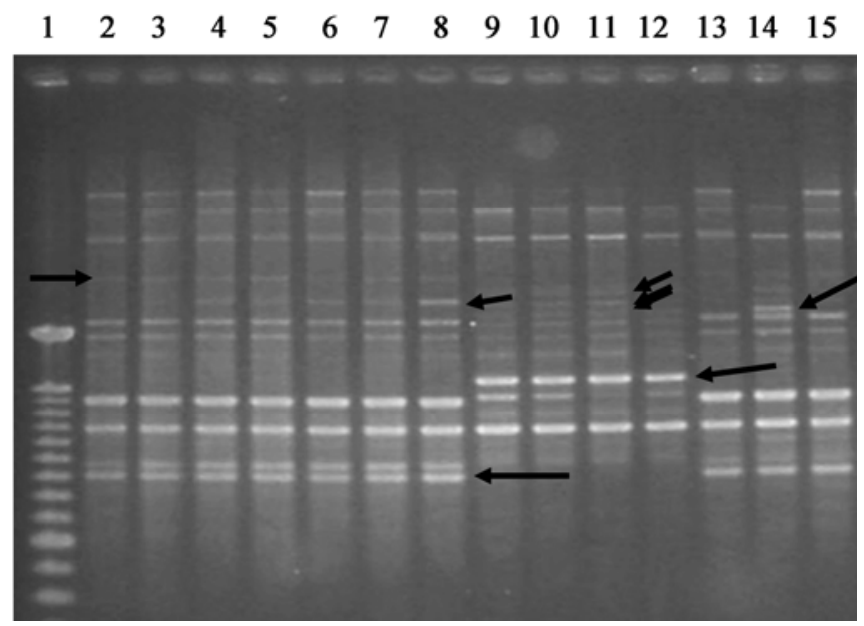

Fig. 3. Agarose gel electrophoresis of total DNA from strains of Pseudomonas syringae pv. actinidiae after BOX-polymerase chain reaction. Lane 1, 100-bp Zymo Research DNA ladder; lane 2, strain 10638; lane 3, 10636; lane 4, 10642; lane 5, 10635; lane 6, 10641; lane 7, 10640; lane 8, 10787; lane 9, 10885; lane 10, 10850; lane 11, 10874; lane 12, 10880; lane 13, 219-1; lane 14, ICMP 9855; and lane 15, IPsa8. Strains in lanes $1-8$ and lanes 13 and 15 are $P$. syringae pv. actinidiae biovar 3. Strains in lanes $9-12$ are $P$. syringae pv. actinidiae biovar 4 . The strain in lane 14 is $P$. syringae pv. actinidiae biovar 1 . Arrows indicate DNA bands unique to strains belonging to the same biovar. two lanes containing a DNA ladder (100-bp DNA ladder from Invitrogen or the ZR 100-bp DNA ladder from Zymo Research).

Sequencing of amplicons. DNA suspensions containing an amplicon to be sequenced were purified using a DNA Clean and Concentrator kit (Zymo Research; PFR) or QIAquick PCR Purification Kit (Qiagen; PHEL). DNA sequencing for PFR was conducted at the Waikato DNA Sequence Facility, Waikato University, New Zealand, and for PHEL at EcoGene, Auckland, New Zealand. When required, the sequences obtained were compared with sequences deposited in GenBank from the National Center for Biotechnology Information using the program BLAST 2.2.25 (45). Multiple alignments were performed with AlignX from VECTOR NTI 11 (Invitrogen). All DNA sequences were deposited in GenBank (JQ934440 to JQ934486).

Pathogenicity assay. A suspension containing the bacterial strain to be tested at approximately $10^{9} \mathrm{CFU} / \mathrm{ml}$ was made in water from freshly grown colonies on $\mathrm{KB}$ plates. These suspensions were sprayed on the abaxial side of unwounded leaves. At least six 3- to 4-month-old seedlings of A. deliciosa 'Bruno' or Hayward or of $A$. chinensis Hort 16A were used per assay. All fully developed leaves were inoculated. When the assays were carried on 1-year-old plants of A. chinensis 'Meteor', five plants per treatment were used. The plants were kept at an average temperature of approximately $20^{\circ} \mathrm{C}$ in plastic chambers to maintain the relative humidity. After 14 or 21 days, each leaf was scored using a 0-to-5 scale reflecting the percentage of the surface area covered with necrotic leaf spots (Fig. 2). All the leaves in a given experiment were scored by the same person. The average score of all the inoculated leaves on a single plant was calculated. The score for a strain was determined as the average score of all the plants of the same cultivar inoculated with that strain. Average leaf severity scores were compared by analysis of variance in Genstat v14 (VSN International). The means were separated by Fisher's least significant differences ( $5 \%$ level).

\section{Results}

Isolation of $P$. syringae pv. actinidiae from different regions of New Zealand. Since November 2010, bacteria that have the biochemical characteristics of $P$. syringae pv. actinidiae (non- or only slightly fluorescent on KB medium, induce HR when infiltrated in tobacco plants, do not have a cytochrome c oxidase or an arginine dehydrolase, produce levan, do not rot potato, do not produce syringomycin, and do not induce ice nucleation) have been isolated from kiwifruit leaves showing angular necrotic leaf spots on vines located in several regions of New Zealand (Fig. 1). In some cases, such bacteria were also isolated from leaves that did

\section{6}

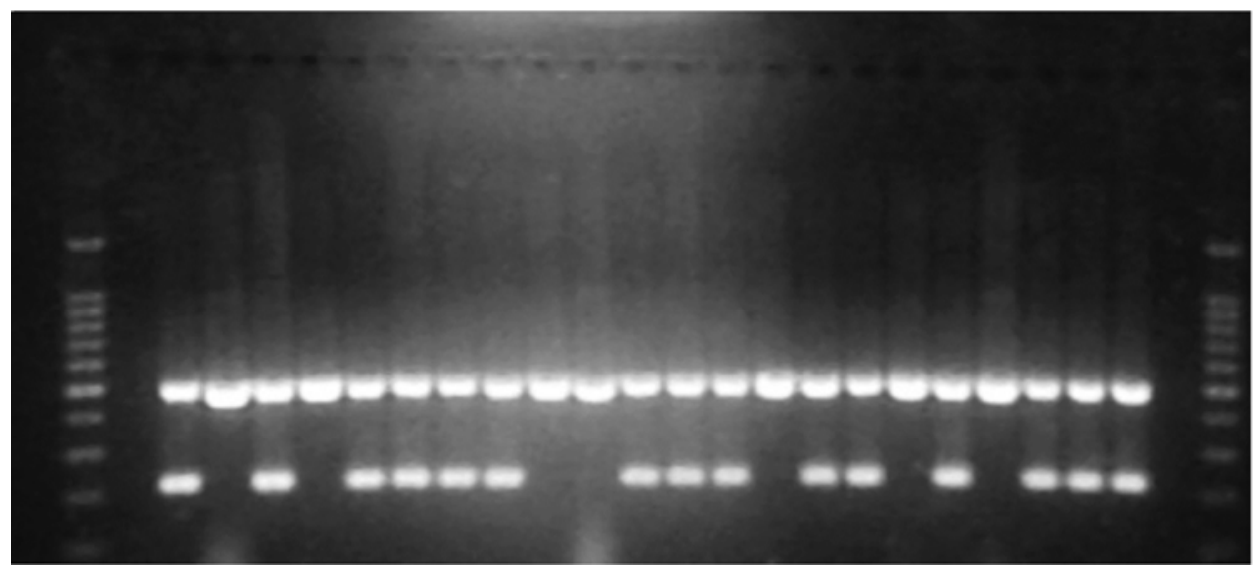

Fig. 4. Agarose gel electrophoresis of Pseudomonas syringae pv. actinidiae after duplex polymerase chain reaction following the protocol described by Gallelli (13). Lanes 1 and 26, 100-bp ladder; lane 2, water control; lane 3, strain 11293; lane 4, 11302; lane 5, 11303; lane 6, 10986; lane 7, 11311; lane 8, 11301; lane 9, 11955; lane 10, 11616; lane 11, 12339; lane 12, 10885; lane 13, 11268; lane 14, 11285; lane 15, 11282; lane 16, 11264; lane 17, 10639; lane 18, 11271; lane 19, 12030; lane 20, 11297; lane 21, 10984; lane 22, 11290; lane 23, 11248; lane 24, 11318; and lane 25, empty. Strains in lanes 4, 6, 11, 12, 16, 19, and 21 are $P$. syringae pv. actinidiae biovar 4; the others are P. syringae pv. actinidiae biovar 3. 
not show any symptoms but where other vines on the orchard were showing leaf spots.

All these strains, regardless of their geographic origin, produced a 280-bp amplicon after PCR using the primers PsaF1/R2 and a 492-bp amplicon when using the Koh and Nou primers. Although both sets of primers were designed to specifically amplify DNA from $P$. syringae pv. actinidiae; neither of them is entirely specific. For example, they can give an amplicon of the right size and similar sequence with strains of other pathovars, such as $P$. syringae $\mathrm{pv}$. theae $(31,37)$. The DNA sequences of the Psa F1/R2 amplicon, which corresponds to part of the $16 \mathrm{~S}-23 \mathrm{~S}$ ribosomal RNA intergenic spacer, of five of the strains isolated in 2010 (10627, 10880, 10988,11251 , and 11955 ) were $100 \%$ similar to one another and to the corresponding DNA fragment of the pathotype strain ICMP 9617 (GenBank AY342165) and to that of the strains isolated from Japan (ICMP 9855), Korea (NIAS 302143 and K-Psa2), France (219-8), and Italy (ISPaVe 019, ISPaVe020, E7, I.25.10.6.6, I.6.5.10, and I.23.6.10).

The DNA sequences of a 800-bp fragment of the 16SrDNA of the nine strains 10627, 10880, 10850, 10988, 11251, 11266, 10638,10787 , and 11298 were $100 \%$ similar to one another and to the 16SrDNA sequences of ICMP 9617, the pathotype strain of $P$. syringae pv. actinidiae (GenBank AB001439.1).

To confirm that those strains were $P$. syringae pv. actinidiae, five strains $(10627,10880,10988,11251$, and 11955) were inoculated onto young Bruno or Hort16A seedlings. They all induced small angular necrotic leaf spots, similar to those seen in infected orchards, and from which $P$. syringae pv. actinidiae could readily be reisolated. These results confirmed the isolates to be $P$. syringae pv. actinidiae.

On that basis, $P$. syringae pv. actinidiae was determined to be present in several regions of New Zealand, including Te Puke in the Bay of Plenty, Hawke's Bay, Waikato, and Motueka in the South Island (Fig. 1). However, during spring (November) 2010, shoot die-back and wilting of canes, sometimes accompanied by production of a red exudate, was detected in only a few orchards of A. chinensis Hort16A in the Bay of Plenty. P. syringae pv. actinidiae could be isolated from such infected canes but not from the red exudate. Similar symptoms on A. deliciosa Hayward vines caused by $P$. syringae pv. actinidiae were not detected until autumn (May) 2011. It was striking that systemic cane infections developed on only a few orchards in the Bay of Plenty, in relatively close proximity to where the first affected orchards were found, but not on Hort16A in the other regions, where presence of $P$. syringae pv. actinidiae had been confirmed (Waikato, Hawke's Bay, and Motueka) but where symptoms had not progressed beyond leaf spots.

To determine whether this difference in symptom development was due to the pathogen or the environment, strains isolated from the Bay of Plenty were compared with strains isolated from other

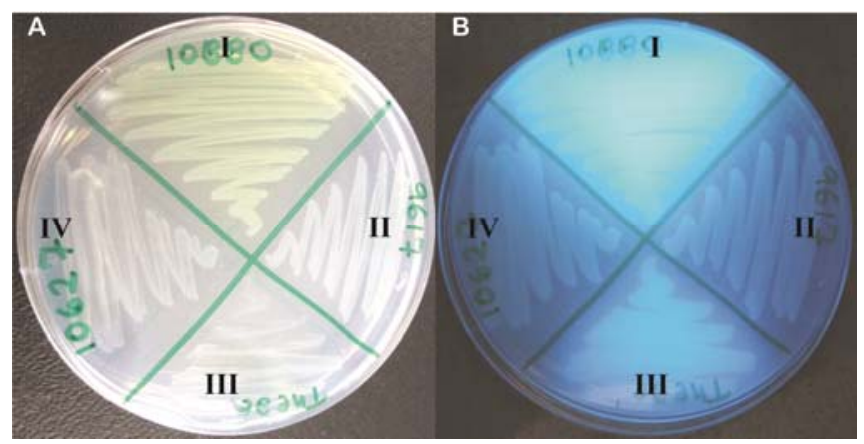

Fig. 5. Morphological characteristics of different biovars of Pseudomonas syringae pv. actinidiae and $P$. syringae pv. theae on King's B medium (A) under natural light or (B) under UV light. Strains 10880 (P. syringae pv. actinidiae biovar 4), ICMP 9617 (P. syringae pv. actinidiae biovar 1 and pathotype of $P$. syringae pv. actinidiae), ICMP3923 (P. syringae pv. theae), and 10627 (P. syringae pv. actinidiae biovar 3) are in quadrants denoted I, II, III, and IV, respectively. regions of New Zealand or from other parts of the Bay of Plenty where systemic cane infection had not been observed.

Identification of two haplotypes of $P$. syringae pv. actinidiae present in New Zealand. Analysis of the DNA sequence of the $c t s$ gene of 44 strains isolated from different regions of New Zealand revealed that there were two different sequences, or $c t s$ haplotypes, differing by 6 bp (Supplementary Figure S1). One of the $c t s$ haplotypes was identical to that found earlier in strains isolated from Italy (2008 outbreak) (41) and from France (2010 outbreak) (36). Only strains isolated from Hort16A orchards in Te Puke that showed cane die-back had this cts haplotype, whereas all other New Zealand strains shared a second, previously undescribed, haplotype. These $c t s$ haplotypes have been numbered from 1 to 3 to reflect the chronology of their identification. The $c t s$ haplotype of the strains of $P$. syringae pv. actinidiae isolated from Japan and from Italy before 2008 is referred to as cts haplotype 1 (previously called haplotype A) (41). Although at least one strain isolated from Korea shares that haplotype, other strains isolated from Korea have a different haplotype, which is called haplotype 2 . These two hap-
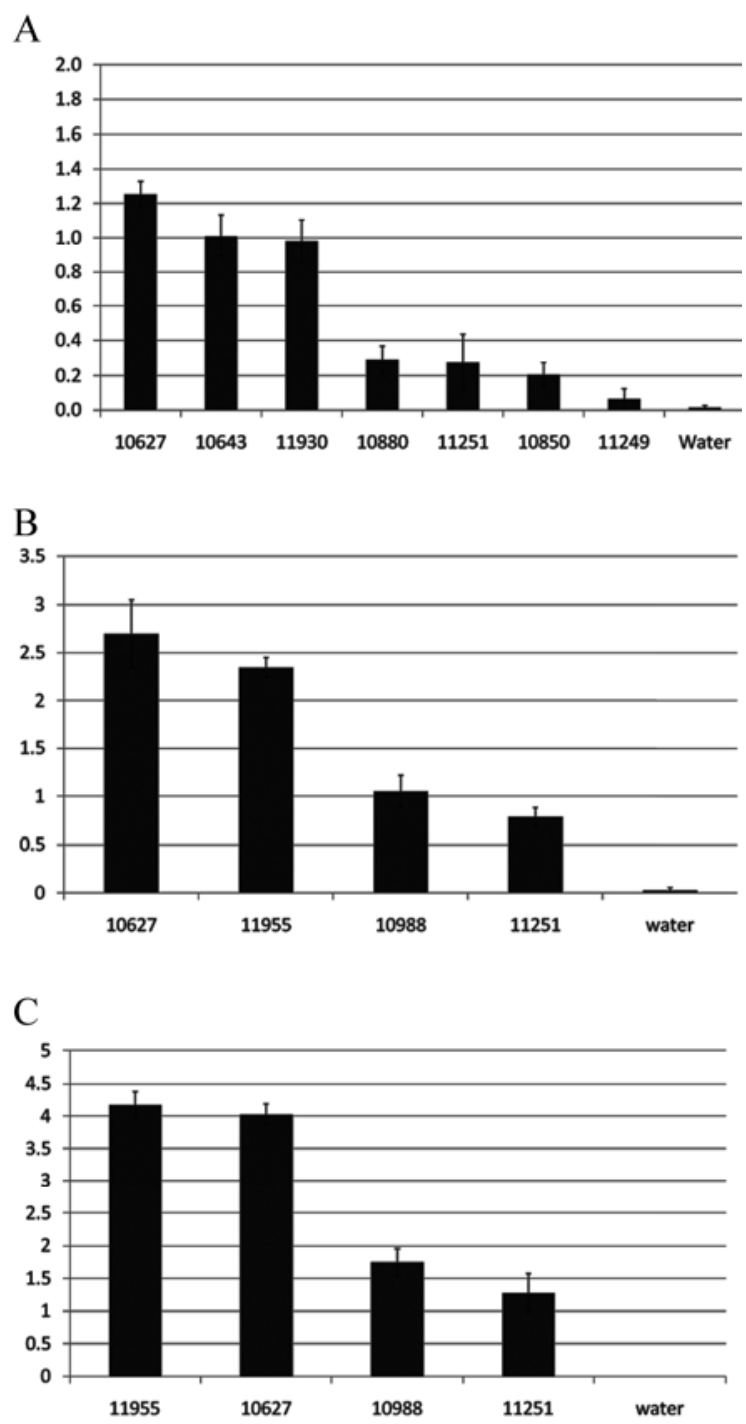

Fig. 6. Pathogenicity of strains of Pseudomonas syringae pv. actinidiae of biovar 3 and biovar 4 on seedlings of A, 'Bruno'; B, 'Hort16A'; or C, 'Hayward'. Results were read 14 days after inoculation for Bruno seedlings and 21 days after inoculation for the two other cultivars. The $y$ axis is the score severity (as defined in Figure 2). Strains 11955, 11930, 10643, and 10627 are $P$. syringae pv. actinidiae biovar 3 and strains $11249,10988,10850,11251$, and 10880 are $P$. syringae pv. actinidiae biovar 4 . Vertical bars represent standard errors of the means. Columns with the same letter are not significantly different at $5 \%$. A, $P<0.001$, least significant difference $(\mathrm{LSD})(5 \%)=0.299 ; \mathrm{B}, P<0.001$, LSD $(5 \%)=0.553 ; \mathrm{C}, P<0.001, \mathrm{LSD}$ $(5 \%)=0.595$. 
lotypes differ from each other by $2 \mathrm{bp}$. The cts haplotype 2 is also shared by strains isolated from Italy since 2008, from France, and from the New Zealand orchards with shoot die-back. This haplotype was previously called haplotype I (41). The $c t s$ haplotype of strains from orchards distributed throughout New Zealand and that has never been described before is referred to as cts haplotype 3. In New Zealand, there is a clear correlation between cts haplotypes and symptom development in orchards of A. chinensis Hort16A. In every orchard where shoot die-back was observed, strains with $c t s$ haplotype 2 were isolated, whereas strains with $c t s$ haplotype 3 were only ever isolated from $A$. chinensis orchards where the disease had not progressed beyond leaf spots. On A. deliciosa, the correlation between symptom development and cts haplotype was less clear because the development of shoot die-back was less common and took longer to develop. However, strains with cts haplotype 3 were never isolated from A. deliciosa vines showing cane wilting or die-back; only strains of cts haplotype 2 have ever been isolated from vines showing such symptoms.

Characterization of the two cts haplotypes present in New Zealand. When the total DNA of 59 strains, including the 44 strains analyzed previously, were analyzed by BOX-PCR, three electrophoretic patterns were detected (Fig. 3). Strains from Japan and Korea, independently of their haplotype, displayed a similar pattern that was different from the pattern displayed by nonKorean strains of $c t s$ haplotype 2. As noted previously, there were very few differences between the BOX-PCR electrophoretic pattern of strains with $c t s$ haplotypes 1 and 2 (41). Most of the DNA banding differences occurred between 1.5 and $3 \mathrm{~kb}$. Strains of cts haplotype 2 had five unique bands, compared with strains of cts haplotype 1 , which had only two unique bands. The differences between the BOX-PCR electrophoretic patterns of strains of cts haplotype 3 and strains of $c t s$ haplotypes 1 and 2 were greater than the differences between the patterns from cts haplotype 1 and 2 . Two major bands between 1.2 and $1 \mathrm{~kb}$ were not present in strains of $c t s$ haplotype 3; however, these strains had an additional band of $1.5 \mathrm{~kb}$ (Fig. 3). The other differences between BOX-PCR profiles were less noticeable and were generally DNA bands between 1.5 and $3 \mathrm{~kb}$.

When using the duplex PCR protocol developed by Gallelli et al. (13), the 15 strains of $c t$ s haplotype 1 and the 32 New Zealand strains of cts haplotype 2 analyzed produced two amplicons of the expected size: $492 \mathrm{bp}$ for the Koh and Nou amplicon and $226 \mathrm{bp}$ for the $a v r D 1$ amplicon (Fig. 4). In contrast, the 13 strains of cts haplotype 3 produced only the 492-bp amplicon, suggesting that the $a v r D 1$ gene is not present in strains of cts haplotype 3. Furthermore, the DNA sequence of the 492-bp Koh and Nou amplicon was not identical for all strains (Supplementary Figure S2). The sequences of five strains of $c t s$ haplotype 2 (including two strains isolated from Italy) were $100 \%$ identical to one another and differed from the sequences of the other strains of $P$. syringae pv. actinidiae by 5 to $7 \mathrm{bp}$. Base pairs at position 191, 200, and 214
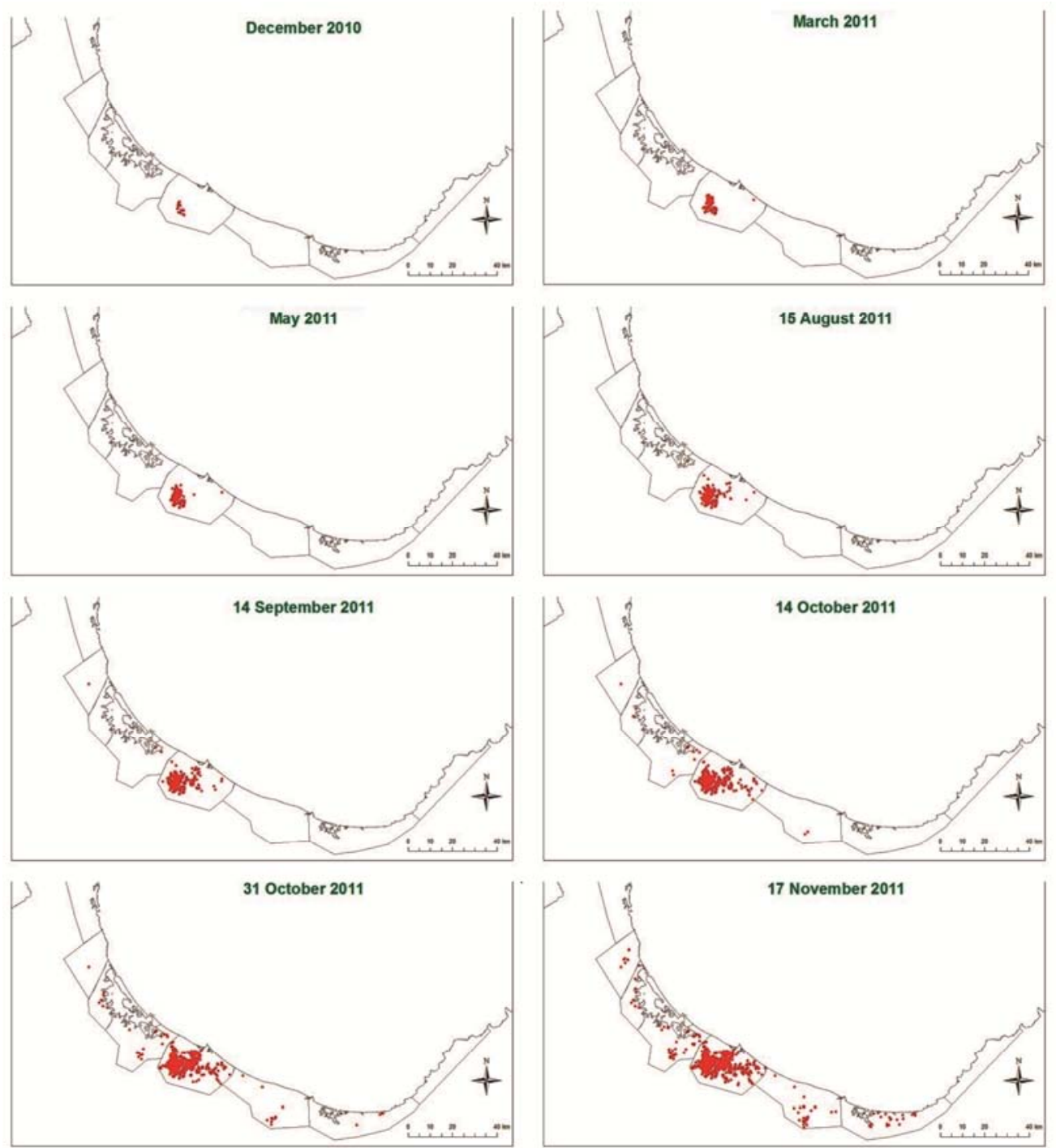

Fig. 7. Progression of bacterial canker of kiwifruit caused by Pseudomonas syringae pv. actinidiae biovar 3 in the Bay of Plenty (North Island, New Zealand) from November 2010 until November 2011. 
were always A, T, and $\mathrm{C}$, respectively, for strains of $c t$ s haplotype 2 and $\mathrm{G}, \mathrm{C}$, and $\mathrm{T}$, respectively, for strains of haplotypes 1 and 3 . DNA sequence analysis revealed that all sequences were similar (98 to $100 \%$ ) to the sequence of the ompP1 found in P. syringae pv. tomato (GenBank FR863686.1), which codes for the outer membrane protein $\mathrm{P} 1$.

The gene hopAl was detected by PCR in all 44 strains isolated from New Zealand but was not detected in strains of $c t$ haplotype
1, including those strains from Italy isolated in 1992 and in strains isolated from Korea. Previous reports that this gene was present in strains isolated in Italy in 1992 (36) were based on strains NCPPB 3871 and NCPPB 3873, which were shown not to be $P$. syringae pv. actinidiae (31).

The morphology of strains of $c t s$ haplotype 3 was slightly different from that of the three other haplotypes (Fig. 5). Strains of $c t s$ haplotype 1 seemed completely nonfluorescent when grown on $\mathrm{KB}$

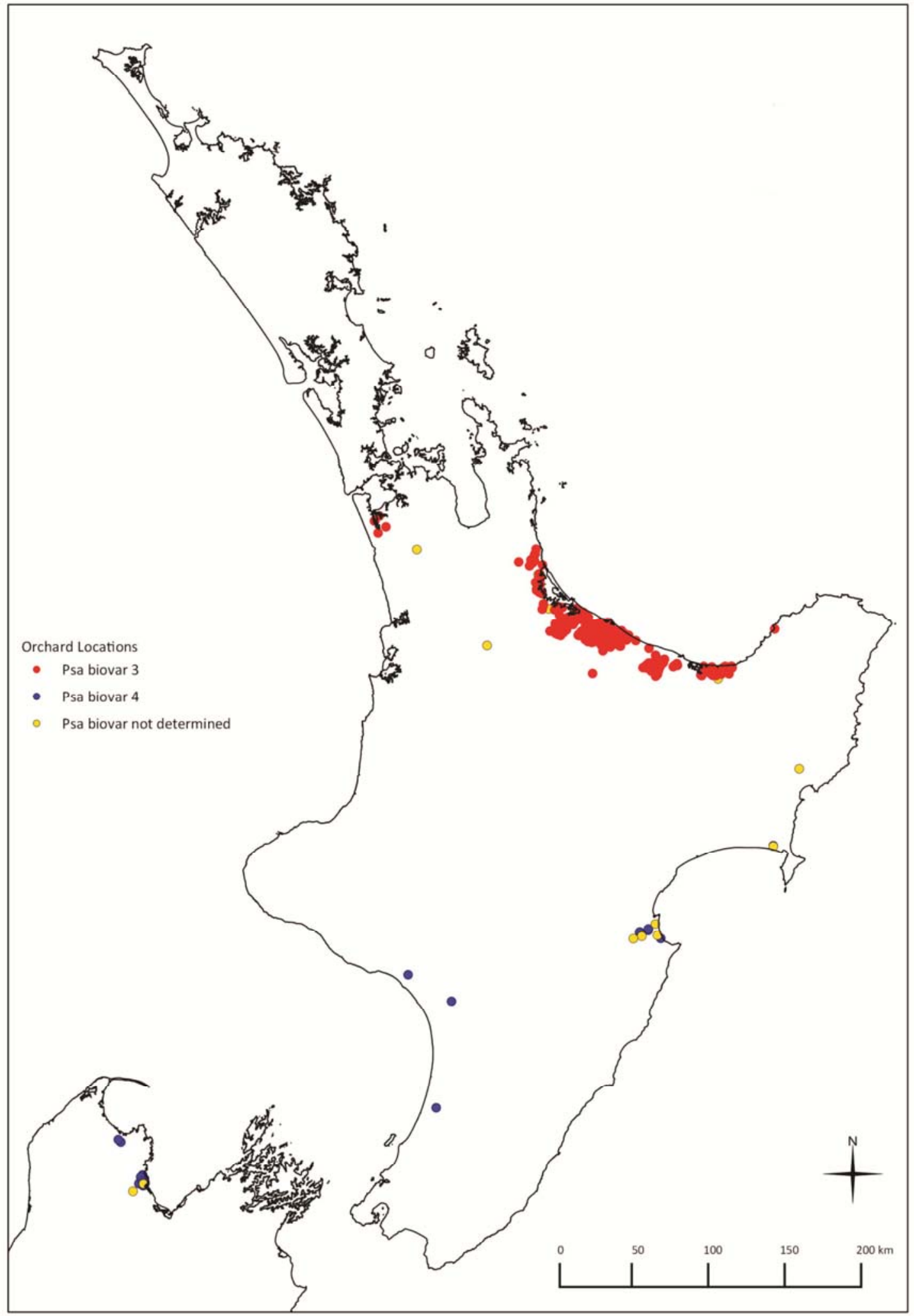

Fig. 8. Map of New Zealand showing the distribution of Pseudomonas syringae pv. actinidiae biovar 3 and biovar 4 as of March 2012. 
medium and exposed to ultraviolet light, whereas those of the cts haplotype 2 were variable, sometimes showing some light-blue fluorescence. Strains of the $c t s$ haplotype 3 consistently produced a green fluorescent pigment. None of the strains of $c t$ haplotype 1 or 2 hydrolyzed esculine but all the strains of haplotype 3 did hydrolyze this compound. None of the 20 strains isolated from New Zealand, randomly selected and representing both haplotypes, was found to be resistant to streptomycin or copper.

Difference in virulence of the two cts haplotypes found in New Zealand. When the New Zealand strains of $c t$ s haplotype 2 (11930, 10643, and 10627) were inoculated onto kiwifruit seedlings of $A$. deliciosa Bruno, they caused significantly more disease than when similar plants were inoculated with the strains of cts haplotype 3 (11249, 10850, 11251, and 10880; Fig. 6A). There were no significant differences between strains of the same haplotype (Fig. 6A). To determine whether this was a specific interaction between bacterial strains and Bruno seedlings, two strains of each cts haplotype (11955 and 10627 for cts haplotype 2 and 10988 and 11251 for $c t s$ haplotype 3) were inoculated onto A. deliciosa Hayward and $A$. chinensis Hort $16 \mathrm{~A}$ seedlings. In both cases, strains of cts haplotype 2 produced significantly more leaf spots than those of cts haplotype 3 (Fig. 6B and C). Similar results were obtained when the strains were inoculated onto potted A. chinensis Meteor plants (data not shown).

Distribution of cts haplotype 2 and 3 of $P$. syringae pv. actinidiae in New Zealand. Molecular characterization of $P$. syringae pv. actinidiae strains (in particular, BOX-PCR electrophoretic pattern and high-resolution melting analysis) isolated from different regions of New Zealand allowed mapping and inference of the progression of $c t$ h haplotype 2 and $c t$ s haplotype 3 in New Zealand (Fig. 7). From November 2010 until August 2011, cts haplotype 2 seemed to be moving relatively slowly and over short distances. Up to early August 2011, its distribution was limited to the Te Puke region: a 10-by-20 km area. However, from September 2011 to November 2011, this pathogen appeared to move more rapidly. It was detected for the first time in Tauranga on 9 August, Waihi on 12 September, Katikati on 27 September, Whakatane on 29 September, and Opotiki on 20 October. By November 2011, 1 year after $P$. syringae pv. actinidiae was first detected in New Zealand, the entire Bay of Plenty was affected by strains of $c t s$ haplotype 2, this haplotype having been isolated from orchards spreading from Waihi to Opotiki, which in a straight line are $145 \mathrm{~km}$ away from each other. Until mid-November 2011, the cts haplotype 2 form of the pathogen was restricted to the Bay of Plenty; however, by the end of November 2011, it had been detected on three orchards in the south of Auckland. In contrast, the distribution of $c t s$ haplotype 3 does not appear to have changed between November 2010 and November 2011, although there is some evidence that orchards in the Te Puke region previously infected with cts haplotype 3 have been overcome with cts haplotype 2. Strains of cts haplotype 3 could not be detected in orchards where cts haplotype 2 was isolated, suggesting that strains of $P$. syringae pv. actinidiae haplotype 2 displaced the strains of haplotype 3 . The distribution of $P$. syringae pv. actinidiae cts haplotype 2 and 3 as of March 2012 is presented in Figure 8.

\section{Discussion}

A. deliciosa Hayward and A. chinensis Hort16A are the two main commercial cultivars of kiwifruit that are grown in New Zealand and elsewhere in the world. Strains of $P$. syringae pv. actinidiae isolated in New Zealand from Hayward and Hort16A were characterized and grouped into two different biovars based on their molecular and pathogenic characteristics. The pathogen was most often isolated from leaves showing necrotic spots. Necrotic spots on kiwifruit leaves can be elliptical, angular, or irregular; large or pinpoint; and with or without a yellow halo surrounding the lesion. The most characteristic leaf spots from which $P$. syringae pv. actinidiae could be isolated were small, angular, and confined by leaf veins. However, no absolute correlation between spot morphology and presence or absence of $P$. syringae pv. actinidiae could be determined (42). P. syringae pv. actinidiae was also isolated from leaves without leaf spots or other signs of infection. This suggests that $P$. syringae pv. actinidiae can live as an epiphyte on kiwifruit. This ability to live epiphytically, a characteristic shared by other pathovars of $P$. syringae (17), might help to explain the rapid spread of the disease in Italy (38) and New Zealand.

P. syringae pv. actinidiae has also been isolated from flowers, including asymptomatic flowers, and from canes (42). The first symptoms on canes of $A$. deliciosa were found several months after the same symptoms had been easily detectable on A. chinensis. The same situation was found in Italy and in France, where the most affected vines in the field were always $A$. chinensis cultivars. In New Zealand up until May 2011, only Hort16A orchards in one small, well-defined region of Te Puke exhibited cane die-back. Other Hort16A orchards, including those in regions where $P$. syringae pv. actinidiae had been found, did not show these symptoms. The first orchards of A. deliciosa displaying similar symptoms of cankers and die-back were located in that same area of Te Puke. The fact that regions with similar host plants and similar climate did not seem to be affected by the disease to the same extent suggested that pathogens with different degrees of virulence could be present in New Zealand.

Strains of $P$. syringae pv. actinidiae isolated in New Zealand were originally characterized by their $c t s$ haplotype. The $c t s$ gene is one of seven housekeeping genes selected for multi-locus sequence typing (MLST) analysis to study the evolutionary relationship among strains of different pathovars of $P$. syringae (32). Housekeeping genes are necessary for bacterial survival; they evolve mostly by neutral mutations, and do not usually transfer horizontally. Therefore, they are very well suited to establish phylogenetic relationships between bacterial strains $(18,32)$. This set of seven genes was later reduced to the four genes $c t s, r p o D$, gyrB, and gapA without any significant reduction in phylogenetic resolution (18). Recently, the phylogenetic relationship of 120 strains of $P$. syringae established by MLST analysis using the concatenated sequences of the four genes $c t s$, $r p o D$, gyrB, and gapA was compared with that obtained using the DNA sequence of the $c t s$ gene alone (29). The strains clustered identically although, on three occasions, clades represented by one strain each were merged into neighboring clades. Therefore, the relationship among strains of $P$. syringae can be determined, to a certain extent, using only the DNA sequence of the $c t s$ gene. Using that approach, strains of $P$. syringae pv. actinidiae isolated from Asia (Japan and one strain from Korea) and the latest Italian outbreak of bacterial canker were organized in two different groups $(38,41)$. These groups were called $c t s$ haplotype A and cts haplotype I, a description which is now outdated. In this article, $c t s$ haplotypes A and I are called cts haplotypes 1 and 2, respectively. Strains of cts haplotype I were responsible for the Italian outbreak of 2008, while the previous Italian outbreaks and the one documented in Asia (Japan and Korea) were linked to strains of $c t s$ haplotype A (41). The separation of the strains of $P$. syringae pv. actinidiae isolated in Italy after 2008 into their own distinct group, separate from the strains isolated in Asia or Italy before 2008, was supported by MLST analysis of housekeeping genes (12), MLST analysis of housekeeping type III effector and phytotoxin genes (5), rep-PCR and IS50-PCR (28) and by analysis of whole-genome sequence of three strains of P. syringae pv. actinidiae: one isolated from Japan, one from Italy in 1992, and one from Italy in 2009 (27). Since the 2010 study (41), most strains isolated from Korea were found to carry cts haplotype 2 (the haplotype of strains isolated from Italy after 2008) but to have a BOX-PCR electrophoretic pattern similar to those of strains isolated from Japan (data not shown). This argues for the strains isolated in Japan and those isolated in Korea to be in two different groups. The separation of the strains of P. syringae pv. actinidiae isolated in Korea from strains isolated in Japan or Italy before 2008 is supported by analysis of the draft genome sequence of one strain of $P$. syringae pv. actinidiae isolated from Korea with the genome of three strains isolated from Japan, two from China, three from Italy in 2008, and one from Portugal (27). It is also 
supported by MLST analysis of housekeeping, type III effector and phytotoxin genes (5).

When strains from the New Zealand outbreak were analyzed, a new $c t s$ haplotype associated with a unique BOX-PCR electrophoretic pattern was found. Other characteristics linked to this haplotype include absence of the effector $a v r D 1$, production of a green fluorescent pigment on $\mathrm{KB}$ medium, ability to hydrolyze esculin, and a lower virulence on several cultivars of A. deliciosa (Hayward and Bruno seedlings) or A. chinensis (Hort16A seedlings and 1year-old Meteor potted plants). However, the most important characteristic of this haplotype is that, in the field, strains of this haplotype have never been linked to any symptom other than leaf spotting.

Strains of $P$. syringae pathovars that exhibit some host specialization can be grouped into races. However, none of the different $c t$ haplotypes of $P$. syringae pv. actinidiae can be differentiated by their ability to cause disease on some species, pathovar, or germplam of Actinidia. They all cause disease to all cultivars of $A$. deliciosa and $A$. chinensis tested today and no plant other than kiwifruit plant has been found susceptible to these pathogens. To use the geographic origin of the first isolate of a cts haplotype to label all the strains of that haplotype, such as Italian strains or Asian strains (as has been done in some media), would be confusing and inadequate. Different haplotypes are present in the same country. For example, strains of cts haplotypes 1 and 2 have been isolated from Italy, and strains of cts haplotypes 2 and 3 have been isolated from New Zealand. Furthermore, such a labeling could also suggest a geographic origin for new outbreaks of the disease. This would be misleading because the geographic origin of the first isolate of a cts haplotype might not be the origin of later outbreaks caused by that cts haplotype. The appellation of Psa V and LV (which have also been used in the media) are not adequate either because they do not distinguish strains of cts haplotypes 1 and 2 . Therefore, we propose to use the term biovar to distinguish the different groups of strains of $P$. syringae pv. actinidiae. Four biovars can be identified, each being defined by a combination of molecular characteristics, including cts haplotype and BOX-PCR electrophoretic pattern, and, sometimes, biochemical characteristics such as fluorescence or ability to hydrolyze esculin. Strains from biovar 1 were initially isolated in Japan and Italy prior to 2008, while the strains from biovar 2 were isolated from Korea. These strains share a similar BOX-PCR pattern but have different cts sequences. Biovars 1 and 2 can also be separated by DNA sequence differences at other housekeeping (acn, pfk, and gapA) and effector (avrDl and $h r p K 1$ ) genes (5). Furthermore, strains from biovar 1 produce phaseolotoxin but not coronatine, whereas strains of biovar 2 produce coronatine but not phaseolotoxin $(5,16)$. No strains of $P$. syringae pv. actinidiae biovars 1 or 2 have been isolated in New Zealand to date. Biovar 3 corresponds to cts haplotype 2; it comprises the strains of $P$. syringae pv. actinidiae isolated from Italy after 2008, France, and New Zealand. It also probably comprises the strains isolated from Portugal, Spain, Switzerland, and Turkey, based on virulence observations in the field and the geographic proximity of these countries to Italy. Outbreaks caused by biovar 3 have had the greatest economic impacts, in both Italy and New Zealand. Strains from biovar 3 do not produce coronatine or phaseolotoxin, nor do strains from biovar 4 . Biovar 4 comprises strains isolated in New Zealand that never lead to symptoms other than leaf spots. Strains of biovar 4 have also been present in Western Australia since 1992, where it has been mistaken for P. viridiflava, a pathogen of limited economic impact, for almost 20 years (7). The limited symptoms caused by strains of biovar 4 render this pathogen inconspicuous. Similarly, strains of $P$. syringae pv. actinidiae biovar 4 may have been in New Zealand for many years, because the presence of biovar 4 in commercial kiwifruit orchards has never been associated with any symptoms other than leaf spots. This hypothesis is supported by the relatively wide distribution of this biovar in New Zealand by December 2010. Moreover, there is some diversity in the sequence of the ompPl amplicon of biovar 4 strains, although no genetic diversity within biovar 4 has been de- tected among five strains characterized at a further 15 housekeeping or effector genes (5).

In contrast, the rapid spread and conspicuous symptoms associated with biovar 3 in New Zealand strongly suggests that this pathogen is a much more recent introduction. In a single year, it has spread from a few orchards centered in Te Puke to the entire Bay of Plenty kiwifruit-growing region, and has recently moved to at least one other region in New Zealand. If biovar 3 had been introduced into New Zealand much earlier than November 2010, it is difficult to imagine that it would not have spread more widely than the few orchards in which it was first detected in November 2010, or that the obvious symptoms it causes on A. chinensis (cane dieback, wilting, canker, and production of a red exudate) would have been overlooked by orchardists for a long period of time.

There are fewer molecular differences between strains of biovars 1,2 , and 3 than between those strains and strains of biovar 4 . This is true for the DNA sequence of the $c t s$ gene, the BOX-PCR electrophoretic pattern, and the DNA sequence of the ompPl gene. This has been confirmed by analyzing the sequences of 15 housekeeping and effector genes in the four biovars of $P$. syringae pv. actinidiae (5).

Strains of biovar 4 are associated with a very low degree of virulence in the field and in the laboratory; they are biochemically different from strains of the other biovars of $P$. syringae pv. actinidiae (e.g., production of a strong green fluorescent pigment on KB medium and hydrolysis of esculin). They also have a lower homology at the cts gene to biovars 1,2 , and 3 than those biovars have with $P$. syringae pv. theae (GenBank accession AY610752.1). Therefore, it is reasonable to question whether biovar 4 is a pathovar of $P$. syringae closely related to but separate from $P$. syringae pv. actinidiae. However, biochemical characteristics are not indicative of a specific pathovar. Pathovars are defined by their host range; to date, there are no indications that strains of biovar 4 have a host range different from that of the other strains of $P$. syringae pv. actinidiae.

The duplex PCR developed by Gallelli et al. (13) can differentiate between strains of the two biovars of $P$. syringae pv. actinidiae present in New Zealand. No amplicons were obtained with the avrD1 primers for strains of biovar 4 , indicating that this gene is not present in those strains. This has been confirmed by PCR (5) using the set of primers for avrDl designed by Ferrante and Scortichini (12). The protocol developed by Gallelli et al. (13) may allow rapid identification by PCR of the two biovars of $P$. syringae pv. actinidiae present in New Zealand without the need to isolate and sequence DNA fragments from a pure bacterial culture. However, it also detects the same false positives as those obtained when using the Koh and Nou primers. When using those primers, an amplicon of the same size as that obtained for strains of $P$. syringae pv. actinidiae (492 bp) was obtained with some strains of $P$. syringae pv. syringae, $P$. syringae pv. tomato (31), and $P$. syringae pv. theae (37). There are now several PCR protocols that have been developed specifically to distinguish strains of biovar 3 from those of biovar 4 (J. F. Mackay, S. Dowlut, J. R. Chapman, and J. L. Vanneste, unpublished data).

Strains from biovar 4 do not seem to possess the effector $a v r D 1$. Whether the presence or absence of a single effector $(a v r D 1)$ can explain the differences in virulence observed in the field and in the laboratory assays has yet to be determined, because this is just one of many molecular differences between the two biovars of $P$. syringae pv. actinidiae present in New Zealand (5).

This study clearly shows that two biovars of $P$. syringae pv. actinidiae are present in New Zealand. These two biovars are different from the two biovars identified in Asia (Japan and Korea). Biovars 1 to 4 correspond to the recently defined multi-locus sequence analysis (MLSA) groups Psa1, Psa2, Psa3, and Psa4, respectively (5). In addition to Japan, Korea, and Europe, P. syringae pv. actinidiae has been identified in Chile (9) and China $(6,24,43)$. The virulent biovar 3 found in New Zealand has also been present in Italy since 2008 (41), France (41), Chile (5), and China (5). However, it is possible that some as-yet-uncharacterized biovars of 
P. syringae pv. actinidiae are also present in these countries, especially China, which is the center of origin of most kiwifruit species, and for which only a single isolate of Psa has currently been characterized.

\section{Acknowledgments}

This work was financially supported by ZESPRI International Ltd. and Kiwifruit Vine Health Inc. (KVH). We thank P. Cosnahan from ZESPRI International Ltd. and $\mathrm{K}$. Lowry from $\mathrm{KVH}$ for their help with the organization of the survey of New Zealand kiwifruit orchards; the staff from ZESPRI and KVH for their assistance in collecting, transporting, and recording the samples; and the staff of Plant \& Food Research and MAF Biosecurity New Zealand for their assistance in isolating $P$. syringae pv. actinidiae.

\section{Literature Cited}

1. Abelleira, A., López, M. M., Peñalver, J., Aguín, O., Mansilla, J. P., Picoaga, A., and García, M. J. 2011. First report of bacterial canker of kiwifruit caused by Pseudomonas syringae pv. actinidiae in Spain. Plant Dis. 95:1583-1583.

2. Balestra, G. M., Mazzaglia, A., Quattrucci, A., Renzi, M., and Rossetti, A. 2009. Current status of bacterial canker spread on kiwifruit in Italy. Australas. Plant Dis. Notes 4:34-36.

3. Balestra, G. M., Renzi, M., and Mazzaglia, A. 2010. First report of bacterial canker of Actinidia deliciosa caused by Pseudomonas syringae pv. actinidiae in Portugal. New Dis. Rep. 22:Article 10.

4. Bastas, K. K., and Karakaya, A. 2011. First report of bacterial canker of kiwifruit caused by Pseudomonas syringae pv. actinidiae in Turkey. Plant Dis. 96:452-452.

5. Chapman, J. R., Taylor, R. K., Weir, B. S., Romberg, M. K., Vanneste, J. L., Luck, J., and Alexander, B. J. R. 2012. Phylogenetic relationships among global populations of Pseudomonas syringae pv. actinidiae Phytopathology 102:1034-1044.

6. Cheng, H., Li, Y., Wan, S., Zhang, J., Ping, Q., Li, G., and Xing, J. 1995. Pathogenic identification of kiwifruit bacterial canker in Anhui. J. Anhui Agric. Univ. http://en.cnki.com.cn/Article_en/CJFDTOTAL-ANHU5003. 006.htm

7. EPPO. 2011. First report of Pseudomonas syringae pv. actinidiae in Australia. EPPO Rep. Serv. 6:2011/2130.

8. EPPO. 2011. First report of Pseudomonas syringae pv. actinidiae in Switzerland. EPPO Rep. Serv. 8:2011/2168.

9. EPPO. 2011. First report of Pseudomonas syringae pv. actinidiae in Chile. EPPO Rep. Serv. 3:2011/2055.

10. Everett, K. R., Taylor, R. K., Romberg, M. K., Rees-George, J., Fullerton, R. A., Vanneste, J. L., and Manning, M. A. 2011. First report of Pseudomonas syringae pv. actinidiae causing kiwifruit bacterial canker in New Zealand. Australas. Plant Dis. Notes 6:67-71.

11. Ferrante, P., and Scortichini, M. 2009. Identification of Pseudomonas syringae pv. actinidiae as causal agent of bacterial canker of yellow kiwifruit (Actinidia chinensis Planchon) in central Italy. J. Phytopathol. 157:768-770.

12. Ferrante, P., and Scortichini, M. 2010. Molecular and phenotypic features of Pseudomonas syringae pv. actinidiae isolated during recent epidemics of bacterial canker on yellow kiwifruit (Actinidia chinensis ) in central Italy. Plant Pathol. 59:954-962.

13. Gallelli, A., L'Aurora, A., and Loreti, S. 2011. Gene sequence analysis for the molecular detection of Pseudomonas syringae pv. actinidiae: developing diagnostic protocols. J. Plant Pathol. 93:425-435.

14. Green, S. J., Michel, F. C., Hadar, Y., and Minz, D. 2004. Similarity of bacterial communities in sawdust- and straw-amended cow manure composts. FEMS Microbiol. Lett. 233:115-123.

15. Gross, D. C., and DeVay, J. E. 1977. Population dynamics and pathogenesis of Pseudomonas syringae in maize and cowpea in relation to the in vitro production of syringomycin. Phytopathology 67:475-483.

16. Han, H. S., Oak, E. J., Koh, Y. J., Hur, J. S., and Jung, J. S. 2003. Characterization of Pseudomonas syringae pv. actinidiae isolated in Korea and genetic relationship among coronatine-producing pathovars based on cmaU sequences. Acta Hortic. 610:403-408.

17. Hirano, S. S., and Upper, C. D. 2000. Bacteria in the leaf ecosystem with emphasis on Pseudomonas syringae - a pathogen, ice nucleus, and epiphyte. Microbiol. Mol. Biol. Rev. 64:624-653.

18. Hwang, M. S. H., Morgan, R. L., Sarkar, S. F., Wang, P. W., and Guttman, D. S. 2005. Phylogenetic characterization of virulence and resistance phenotypes of Pseudomonas syringae. Appl. Environ. Microbiol. 71:51825191.

19. King, E. O., Ward, M. K., and Raney, D. E. 1954. Two simple media for the demonstration of pyocyanin and fluorescin. J. Lab. Clin. Med. 44:301-307.

20. Koh, Y. J., Cha, B. J., Chung, H. J., and Lee, D. H. 1994. Outbreak and spread of bacterial canker in kiwifruit. Korean J. Plant Pathol. 10:68-72.

21. Koh, Y. J., Jung, J. S., and Hur, J. S. 2003. Current status of occurrence of major diseases on kiwifruits and their control in Korea. Acta Hortic. 610:437-443
22. Koh, Y. J., and Nou, I. S. 2002. DNA markers for identification of Pseudomonas syringae pv. actinidiae. Mol. Cells 13:309-314.

23. Lelliott, R. A., Billing, E., and Hayward, A. C. 1966. A determinative scheme for the fluorescent plant pathogenic pseudomonads. J. Appl. Bacteriol. 29:470-489.

24. Liang, Y., Zhang, X., Tian, C., Gao, A., and Wang, P. 2000. Pathogenic identification of kiwifruit bacterial canker in Shaanxi. J. Northwest For College. http://en.cnki.com.cn/Article_en/CJFDTOTAL-XBLX200001006. htm

25. Lindow, S. E., Arny, D. C., and Upper, C. D. 1978. Erwinia herbicola: a bacterial ice nucleus active is increasing frost injury to corn. Phytopathology 68:523-527.

26. Louws, F. J., Fulbright, D. W., Stephens, C. T., and de Bruijn, F. J. 1994. Specific genomic fingerprints of phytopathogenic Xanthomonas and Pseudomonas pathovars and strains generated with repetitive sequences and PCR. Appl. Environ. Microbiol. 60:2286-2295.

27. Marcelletti, S., Ferrante, P., Petriccione, M., Firrao, G., and Scortichini, M. 2011. Pseudomonas syringae pv. actinidiae draft genomes comparison reveal strain-specific features involved in adaptation and virulence to Actinidia species. PLoS ONE 6:e27297.

28. Mazzaglia, A., Renzi, M., and Balestra, G. M. 2011. Comparison and utilization of different PCR-based approaches for molecular typing of Pseudomonas syringae pv. actinidiae strains from Italy. Can. J. Plant Pathol. 33:818.

29. Morris, C. E., Sands, D. C., Vanneste, J. L., Montarry, J., Oakley, B., Guilbaud, C., and Glaux, C. 2010. Inferring the evolutionary history of the plant pathogen Pseudomonas syringae from its biogeography in headwaters of rivers in North America, Europe, and New Zealand. MBio 1(3): e0010710-e00107-20. doi:10.1128/mBio.00107-10

30. Muyzer, G., and Ramsing, N. B. 1995. Molecular methods to study the organization of microbial communities. Water Sci. Technol. 32:1-9.

31. Rees-George, J., Vanneste, J. L., Cornish, D. A., Pushparajah, I. P. S., Yu, J., Templeton, M. D., and Everett, K. R. 2010. Detection of Pseudomonas syringae pv. actinidiae using polymerase chain reaction (PCR) primers based on the 16S-23S rDNA intertranscribed spacer region and comparison with PCR primers based on other gene regions. Plant Pathol. 59:453-464.

32. Sarkar, S. F., and Guttman, D. S. 2004. Evolution of the core genome of Pseudomonas syringae, a highly clonal, endemic plant pathogen. Appl. Environ. Microbiol. 70:1999-2012.

33. Scortichini, M. 1994. Occurrence of Pseudomonas syringae pv. actinidiae on kiwifruit in Italy. Plant Pathol. 43:1035-1038.

34. Serizawa, S., Ichikawa, T., Takikawa, Y., Tsuyumu, S., and Goto, M. 1989. Occurrence of bacterial canker of kiwifruit in Japan: description of symptoms, isolation of the pathogen and screening of bactericides. Ann. Phytopathol. Soc. Jpn. 55:427-436.

35. Takikawa, Y., Serizawa, S., Ichikawa, T., Tsuyumu, S., and Goto, M. 1989. Pseudomonas syringae pv. actinidiae pv. nov.: the causal bacterium of canker of kiwifruit in Japan. Ann. Phytopathol. Soc. Jpn. 55:437-444.

36. Vanneste, J. L., Cornish, D. A., Yu, J., Audusseau, C., Paillard, S., Rivoal, C., and Poliakoff, F. 2011. Presence of the effector gene hopAl in strains of Pseudomonas syringae pv. actinidiae isolated from France and Italy. N. Z. Plant Prot. 64:252-258

37. Vanneste, J. L., Cornish, D. A., Yu, J., and Morris, C. E. 2009. The application of polymerase chain reaction for characterising strains of Pseudomona syringae isolated from New Zealand rivers. N. Z. Plant Prot. 62:256-261.

38. Vanneste, J. L., Kay, C., Onorato, R., Yu, J., Cornish, D. A., Spinelli, F., and Max, S. 2011. Recent advances in the characterisation and control of Pseudomonas syringae pv. actinidiae, the causal agent of bacterial canker on kiwifruit. Acta Hortic. 913:443-456.

39. Vanneste, J. L., Paulin, J. P., and Expert, D. 1990. Bacteriophage Mu as a genetic tool to study Erwinia amylovora pathogenicity and hypersensitive reaction on tobacco. J. Bacteriol. 172:932-941.

40. Vanneste, J. L., Poliakoff, F., Audusseau, C., Cornish, D. A., Paillard, S., Rivoal, C., and Yu, J. 2011. First report of Pseudomonas syringae pv. actinidiae, the causal agent of bacterial canker of kiwifruit in France. Plant Dis. 95:1311-1311.

41. Vanneste, J. L., Yu, J., and Cornish, D. A. 2010. Molecular characterisations of Pseudomonas syringae pv. actinidiae strains isolated from the recent outbreak of bacterial canker on kiwifruit in Italy. N. Z. Plant Prot. 63:7-14.

42. Vanneste, J. L., Yu, J., Cornish, D. A., Max, S., and Clark, G. 2011. Presence of Pseudomonas syringae pv. actinidiae, the causal agent of bacterial canker of kiwifruit, on symptomatic and asymptomatic tissues of kiwifruit. N. Z. Plant Prot. 64:241-245.

43. Wang, Z., Tang, X., and Liu, S. 1992. Identification of the pathogenic bacterium for bacterial canker on Actinidia in Sichuan. J. Southwest Agric. Univ. http://en.cnki.com.cn/Article en/CJFDTOTAL-XNND199206007.htm

44. Wilson, M., and Lindow, S. E. 1993. Interactions between the biologicalcontrol agent Pseudomonas-fluorescens A506 and Erwinia-amylovora in pear blossoms. Phytopathology 83:117-123.

45. Zhang, Z., Schwartz, S., Wagner, L., and Miller, W. 2000. A greedy algorithm for aligning DNA sequences. J. Comput. Biol. 7:203-214. 